\title{
Modelling and Optimization for Heat Treatment of Al-Si-Mg Alloy Prepared by Indirect Squeeze Casting Based on Response Surface Methodology
}

\author{
Liwen Chen ${ }^{a}$, Yuhong Zhao ${ }^{a}$, Zhiqin Wen ${ }^{a}$, Jinzhong Tian ${ }^{a}, \mathrm{Hua} \mathrm{Hou}^{a}$ \\ ${ }^{a}$ School of Materials Science and Engineering, North University of China, Taiyuan 030051, China
}

Received: March 18, 2017; Revised: June 05, 2017; Accepted: June 20, 2017

\begin{abstract}
The purpose of the present study is to model and analyze heat treatment process of Al-Si-Mg alloy prepared by indirect squeeze casting. The combined effects of whole heat treatment process, including solution treatment temperature, solution treatment time, ageing temperature and ageing time, on Vickers hardness, were investigated. The non-linear mathematical model has been developed through BoxBehnken design based on response surface methodology. The results of ANOVA tests have proven the model is capable of making accurate predictions and statistically adequate. The significance tests show all four process parameters significantly affect response value and the relationship might be non-linear in nature. The dimensional response surface and matching contour plots are drawn, establishing an evaluation of the interaction effects of process parameters. The optimum heat treatment process is found as solution treatment temperature of $540.28^{\circ} \mathrm{C}$, solution treatment time of $7.55 \mathrm{~h}$, ageing temperature of $174.23^{\circ} \mathrm{C}$, and ageing time of $8.61 \mathrm{~h}$.
\end{abstract}

Keywords: Al-Si-Mg alloy, Response surface methodology, Indirect squeeze casting, HV

\section{Introduction}

In recent years, there is a large demand for lightweight components with high mechanical capacity. The density of aluminum is one-third of the steel or cast iron, and the trend is to substitute cast iron components with aluminum components produced by squeeze casting. Squeeze casting (SC) is an advanced special casting technique that the molten metal is filled into the mold slowly and solidified under highpressure. The applied pressure in squeeze casting leads to an obvious decrease of the secondary dendrite arm spacing and disappearance of micro-porosity in the casting, which are the main reasons for the improvement of mechanical properties ${ }^{1}$.

Due to the low porosity rate in the squeeze casting parts, heat treatment can be applied, which can further improve the mechanical performance ${ }^{2}$. The heat treatment of Al-Si-Mg alloys prepared by squeeze casting involves the following procedures: solution treatment, quenching, and ageing.

Solution treatment involves soaking at a relatively high temperature to the dissolution of Mg-rich particles generated during the stage of solidification and redistribution of solute atoms to achieve a homogeneous and high concentration of alloying elements in matrices. The maximum solution treatment temperature decided by the alloy composition is as close to the eutectic temperature as possible while avoiding incipient melting of phases. Mg-containing phases formed during solidification are $\mathrm{Mg}_{2} \mathrm{Si}$ and the $\pi-\mathrm{Al}_{8} \mathrm{Mg}_{3} \mathrm{FeSi}_{6}$ phase. Dissolution and homogenization of $\mathrm{Mg}_{2} \mathrm{Si}$ particles are a fast process ${ }^{3}$. Rometsch et al. ${ }^{4}$ found that dissolution of the $\mathrm{Mg}_{2} \mathrm{Si}$ phase was completed within 2-4 minute and homogenization was finished within 8-15 minute in the A356 alloy. The particles of $\pi-\mathrm{Al}_{8} \mathrm{Mg}_{3} \mathrm{FeSi}_{6}$ phase are hard to dissolve and they can transform into $\beta-\mathrm{Al}_{5} \mathrm{FeSi}$ phase while reducing the $\mathrm{Mg}$ concentration in the alloy (0.3-0.4wt.\%). The $\beta-\mathrm{Al}_{5} \mathrm{FeSi}$ phase particles fragment and gradually dissolve

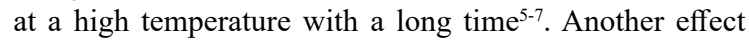
of solution treatment is spheroidization of eutectic silicon particles. According to Shivkumar et al..$^{8}$, the optimal time for a sand-cast Sr-modified A356 alloy is $3-6 \mathrm{~h}$ at $540{ }^{\circ} \mathrm{C}$. The time can be further reduced if the microstructure is finer ${ }^{9}$.

Quenching is able to form supersaturated solid solution including a great number of vacancies from the high solution treatment temperature to room temperature. Seifeddine et al. and Emadi et al. ${ }^{10,11}$ found the effect of quench rate and $\mathrm{Mg}$ concentration on mechanical properties was significant.

The purpose of ageing treatment is to obtain uniform distribution of precipitates. For Al-Si-Mg alloys, the precipitation sequence begins with the formation of spherical GP zones which is formed from an enrichment of Si and $\mathrm{Mg}$ atoms. Then the GP zones develop into needle-shaped coherent $\beta^{\prime \prime}$ phase. The coherent $\beta^{\prime \prime}$ phase grows to semicoherent $\beta^{\prime}$ phase and ultimately non-coherent $\beta$ phase ${ }^{12}$. If artificial ageing temperatures with the range of $170-200^{\circ} \mathrm{C}$ are applied, comparable strength levels can be achieved. If a relatively high temperature is applied the ageing time can be shortened. The time required to peak hardness is about $10 \mathrm{~h}$ at $170^{\circ} \mathrm{C}$, while it is only 20 minute at $210^{\circ} \mathrm{C}^{13,14}$. However, a decrease in performance is discovered if the temperature is increased to $210^{\circ} \mathrm{C}$ because the $\beta^{\prime \prime}$ phase change to the $\beta^{\prime}$ phase when temperatures over $200^{\circ} \mathrm{C}^{15}$. 
It is noted that, the effects of different heat treatment process parameters on alloy performance are reported in the literature widely. However, there is not sufficient to consider only one or two parameters. It is of vital importance to take the whole heat treatment process into consideration in order to achieve the optimal performance of Al-Si-Mg alloy.

Orthogonal array designs are commonly used for experiments but limited in number and may fail to test all interaction effect of the process variables under investigation ${ }^{16}$. Many experimental investigations have been conducted using a two-level factorial design for studying the influence of heat treatment on mechanical properties. However, with this approach, it is possible to develop only linear input-output relationships. For investigating the nonlinearity of output characteristics, each factor is required at least three levels ${ }^{17}$. The number of experiments increases with the increase in number of parameters and their levels (Refer equation (1))

$$
\text { Number of experiments }=(\text { Levels })^{\text {Factors }}
$$

RSM is the regression analysis probing the relationships between one or more response variables and several explanatory variables. The essential of RSM is that establishing an approximate mathematical model to replace a complex one based on results estimated at various points in the design space $^{18}$.

The purpose of the present study is to develop Vickers hardness $(H V)$ prediction model for heat treatment of indirect squeeze casting $\mathrm{Al}-\mathrm{Si}-\mathrm{Mg}$ alloy. The factors studied are solution treatment temperature, solution treatment time, ageing temperature and ageing time. The Vickers hardness is the response studied and design of experiments is established through RSM based on BBD.

\section{Experimental Procedure}

\subsection{Materials and equipment}

The raw material used in the present study was an $\mathrm{Al}-\mathrm{Si}-$ $\mathrm{Mg}$ alloy. The alloy composition, measured using an optical emission spectrometer, is shown in Table 1.

Table 1. Nominal composition of Al-Si-Mg alloy used in this study $(\mathrm{wt} \%)$

\begin{tabular}{ccccccccc}
\hline Element & $\mathrm{Si}$ & $\mathrm{Mg}$ & $\mathrm{Cu}$ & $\mathrm{Fe}$ & $\mathrm{Mn}$ & $\mathrm{Ti}$ & $\mathrm{Zn}$ & $\mathrm{Al}$ \\
\hline Content & 7.50 & 0.31 & 0.20 & 0.16 & 0.04 & 0.03 & 0.01 & Bal. \\
\hline
\end{tabular}

Multifunctional squeeze casting machine was applied on purpose to manufacture specimens for the study. The maximum clamping force and maximum plunger injection force are $5000 \mathrm{KN}$ and $2000 \mathrm{KN}$ respectively. Ring parts castings were fabricated by the machine. The overall dimension of the casting is $\varphi 256 \mathrm{~mm} \times 53 \mathrm{~mm}$ and the projected area of mould joint is $26544 \mathrm{~mm}^{2}$. The ring parts casting connects with gating system which is consist of sprue, runner and ingate with the same cross section (as shown in Figure 1).

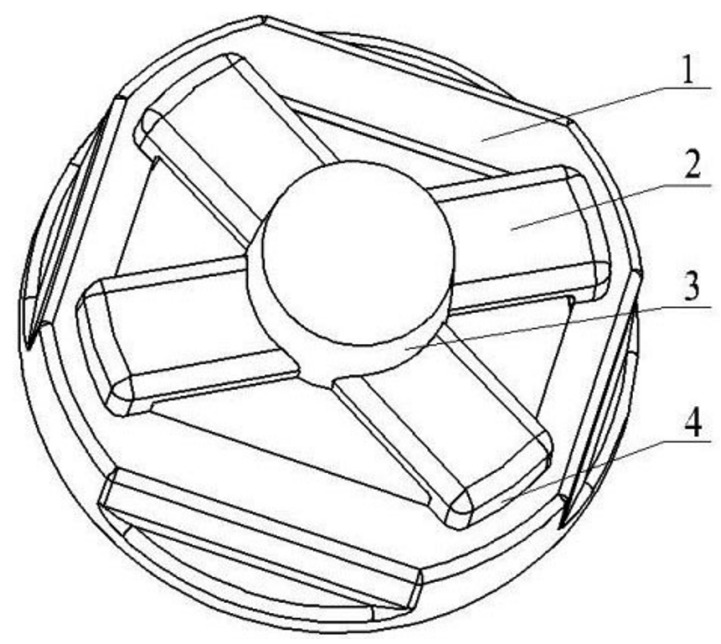

Figure 1. The structure and gating system of ring parts casting. 1 - ring parts casting 2 - runner 3 - sprue 4 - ingate

Alloy was melted in a medium frequency furnace inside a graphite crucible. The die was preheated by resistant heating. The structure of the die is shown in Figure 2. Subsequently, the molten metal was poured into the mould. The pressure was applied directly on the sprue via a plunger and transferred from runner to the solidifying casting. After solidification, the casting was ejected by ejector plate connected to tie bar which is driven by hydraulic cylinders.

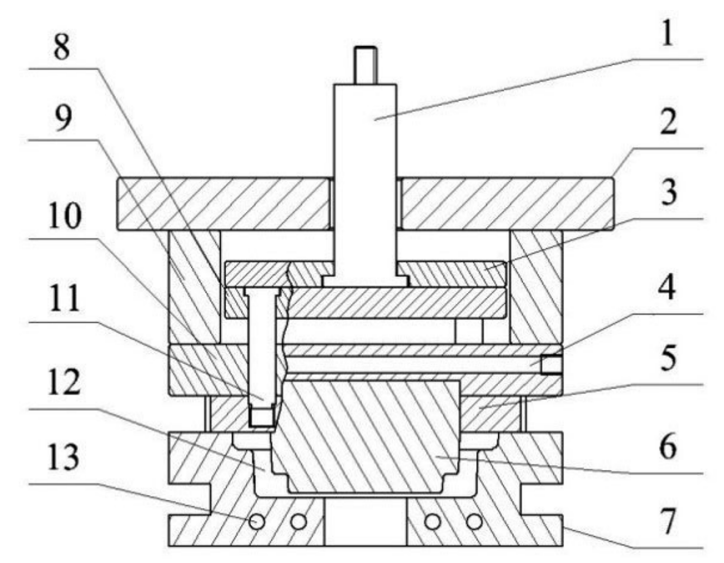

Figure 2. The structure of the die. 1-tie bar; 2- backboard; 3- ejectup-plate; 4- resistant heating hole; 5 - ejector plate; 6- movable die core; 7- fixed die; 8- eject-down-plate; 9- rail; 10- movable die plate; 11 - connection guide pin; 12 - cavity; 13- resistant heating hole

The melt temperature and the mold temperature were $700^{\circ} \mathrm{C}$ and $150^{\circ} \mathrm{C}$, respectively, and the applied pressure was $100 \mathrm{MPa}$. The injection speed of plunger was $0.38 \mathrm{~mm} / \mathrm{s}$. The pressure was applied for 30 s and the casting was ejected by ejector plate. 
Specimens of the casting have been taken at eight different locations to heat treatment (see Figure 3). The heat treatment experiments have been conducted as BBD matrices and two replicates have been considered for each parameter condition. Following solution heat treatment, specimens were water quenched for 3 minutes with water temperature of $65^{\circ} \mathrm{C}$, and then the ageing treatment was performed. After heat treatment, the Vickers hardness of Specimens were measured at ten different location which made a cross at the point. To reduce the variation, an average of 20 different values was taken for each parameter condition.

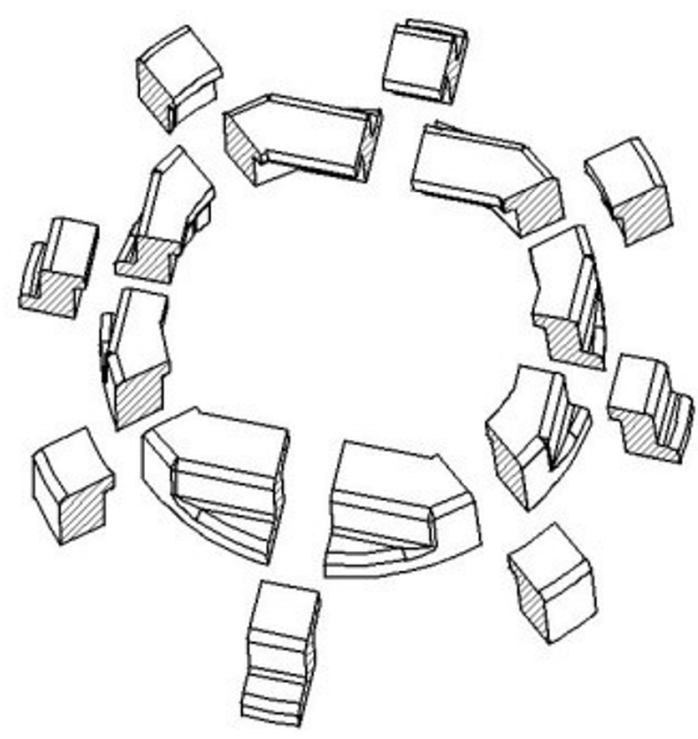

Figure 3. Sampling schematic

\subsection{Response surface methodology}

In order to study the effect of heat treatment on the Vickers hardness, four principal parameters, including solution treatment temperature $\left(T_{\mathrm{s}}\right)$, solution treatment time $\left(t_{\mathrm{s}}\right)$, ageing temperature $\left(T_{\mathrm{a}}\right)$ and ageing time $\left(t_{\mathrm{a}}\right)$, are specified as heat treatment process parameters. The desired response is the $H V$ which is assumed to be influenced by the above four parameters.

In the RSM, The general form describing $Y$ (response) expressed as a function of process variables $\left(T_{\mathrm{s}}, t_{\mathrm{s}}, T_{\mathrm{a}}\right.$ and $t_{\mathrm{a}}$ ) is shown below:

$$
Y=F\left(T_{S}, t_{S}, T_{a}, T_{a}\right)
$$

Where $\mathrm{F}$ is the response function and $Y$ is the desired response value. The approximation of $Y$ is devised using the fitted second-order polynomial regression model which is named the quadratic model. The quadratic model of response value can be transformed as follows ${ }^{19}$ :

$$
Y=\alpha_{0}+\sum_{i=1}^{4} \alpha_{i} X_{i}+\sum_{i=1}^{4} \alpha_{i i} X_{i}^{2}+\sum_{i<j}^{4} \alpha_{i j} X_{i} X_{j}
$$

The term, $\alpha_{0}, \alpha_{i}, \alpha_{i i}$ and $\alpha_{i j}$ are the coefficients of the regression equations and are computed using the least square method. Where $\alpha_{0}$ is constant, $\alpha_{\mathrm{i}}, \alpha_{\mathrm{ii}}$ and $\alpha_{\mathrm{ij}}$ represent the coefficients of linear, quadratic and cross product terms, respectively. $X_{\mathrm{i}}$ represents the coded variables which correspond to the studied process parameters. The coded variables $X_{\mathrm{i}}$, $\mathrm{i}=1,2,3,4$ are calculated from the next transformation equations:

$$
\begin{gathered}
X_{1}=\frac{T_{S}-T_{S 0}}{\Delta T_{S}} \\
X_{2}=\frac{t_{S}-t_{S 0}}{\Delta t_{S}} \\
X_{3}=\frac{T_{a}-T_{a 0}}{\Delta T_{a}} \\
X_{4}=\frac{t_{a}-t_{a 0}}{\Delta t_{a}}
\end{gathered}
$$

$X_{1}, X_{2}, X_{3}$ and $X_{4}$ are the coded values of process parameters $T_{\mathrm{s}}, t_{\mathrm{s}}, T_{\mathrm{a}}$ and $t_{\mathrm{a}}$, respectively. $T_{\mathrm{s} 0}, t_{\mathrm{s} 0}, T_{\mathrm{a} 0}$ and $t_{\mathrm{a} 0}$ are the values of $T_{\mathrm{s}}, t_{\mathrm{s}}, T_{\mathrm{a}}$ and $t_{\mathrm{a}}$ at the center level. $\Delta T_{\mathrm{s}}, \Delta t_{\mathrm{s}}, \Delta T_{\mathrm{a}}$ and $\Delta t_{\mathrm{a}}$ are the intervals of variation in $T_{\mathrm{s}}, t_{\mathrm{s}}, T_{\mathrm{a}}$ and $t_{\mathrm{a}}$, respectively.

BBD consisting of 30 experiments was conducted for developing the regression model for $H V$. The input parameters and their levels used for this work are given in Table 2. The experimental levels for each variable were selected based on results of preliminary experiments and literature values.

Table 2. Input parameters and their levels

\begin{tabular}{lcccc}
\hline S.no. & Parameter & $\begin{array}{c}\text { Low level } \\
(-1)\end{array}$ & $\begin{array}{c}\text { Center } \\
\text { level }(0)\end{array}$ & $\begin{array}{c}\text { High level } \\
(1)\end{array}$ \\
\hline 1 & $T_{s}\left({ }^{\circ} \mathrm{C}\right)$ & 510 & 530 & 550 \\
2 & $t_{s}(\mathrm{~h})$ & 5 & 7 & 9 \\
3 & $T_{a}\left({ }^{\circ} \mathrm{C}\right)$ & 150 & 170 & 190 \\
4 & $t_{a}(\mathrm{~h})$ & 6 & 8 & 10 \\
\hline
\end{tabular}

\section{Results and Discussion}

The experimental results of $H V$ with designed matrix are shown in Table 3. The non-linear mathematical model based on BBD has been developed for the response surface $H V$ with the process parameters set at three levels. Significance and ANOVA tests have been carried out to check the statistical adequacy of the models.

\subsection{Statistical analysis and develop of prediction model}

Summary table of ANOVA is established to summarize the test of the prediction model. As is shown in Table 4, the P-value for the term of the model is less than 0.05 and 
Table 3. Design matrix and experimental results

\begin{tabular}{|c|c|c|c|c|c|c|c|c|c|}
\hline \multirow{2}{*}{ Test no. } & \multicolumn{4}{|c|}{ Code factors } & \multicolumn{4}{|c|}{ Actual factors } & \multirow{2}{*}{$\begin{array}{c}\text { Response } \\
\mathrm{HV}\end{array}$} \\
\hline & $X_{1}$ & $X_{2}$ & $X_{3}$ & $X_{4}$ & $T_{s}$ & $t_{s}$ & $T_{a}$ & $t_{a}$ & \\
\hline $\mathrm{T} 1$ & 0 & 0 & 1 & -1 & 530 & 7 & 190 & 6 & 107.75 \\
\hline $\mathrm{T} 2$ & 0 & 0 & 0 & 0 & 530 & 7 & 170 & 8 & 126.89 \\
\hline $\mathrm{T} 3$ & 0 & 0 & 0 & 0 & 530 & 7 & 170 & 8 & 130.92 \\
\hline $\mathrm{T} 4$ & 0 & 1 & 0 & 1 & 530 & 9 & 170 & 10 & 120.47 \\
\hline T5 & 0 & 0 & 0 & 0 & 530 & 7 & 170 & 8 & 130.83 \\
\hline T6 & -1 & 0 & 1 & 0 & 510 & 7 & 190 & 8 & 112.27 \\
\hline $\mathrm{T} 7$ & 0 & 1 & 0 & -1 & 530 & 9 & 170 & 6 & 108.07 \\
\hline $\mathrm{T} 8$ & 0 & -1 & 0 & 1 & 530 & 5 & 170 & 10 & 102.53 \\
\hline T9 & 0 & 0 & -1 & 1 & 530 & 7 & 150 & 10 & 108.43 \\
\hline $\mathrm{T} 10$ & 1 & 0 & -1 & 0 & 550 & 7 & 150 & 8 & 109.10 \\
\hline T11 & 0 & 0 & 0 & 0 & 530 & 7 & 170 & 8 & 126.86 \\
\hline $\mathrm{T} 12$ & 0 & 1 & -1 & 0 & 530 & 9 & 150 & 8 & 109.09 \\
\hline $\mathrm{T} 13$ & -1 & 1 & 0 & 0 & 510 & 9 & 170 & 8 & 118.90 \\
\hline $\mathrm{T} 14$ & -1 & 0 & -1 & 0 & 510 & 7 & 150 & 8 & 103.80 \\
\hline $\mathrm{T} 15$ & 0 & 0 & -1 & -1 & 530 & 7 & 150 & 6 & 101.17 \\
\hline T16 & 1 & 0 & 0 & 1 & 550 & 7 & 170 & 10 & 124.04 \\
\hline $\mathrm{T} 17$ & 0 & -1 & -1 & 0 & 530 & 5 & 150 & 8 & 104.08 \\
\hline T18 & -1 & -1 & 0 & 0 & 510 & 5 & 170 & 8 & 107.21 \\
\hline T19 & 0 & 0 & 0 & 0 & 530 & 7 & 170 & 8 & 129.32 \\
\hline $\mathrm{T} 20$ & 1 & 0 & 1 & 0 & 550 & 7 & 190 & 8 & 124.69 \\
\hline $\mathrm{T} 21$ & 0 & 0 & 1 & 1 & 530 & 7 & 190 & 10 & 116.92 \\
\hline $\mathrm{T} 22$ & 0 & -1 & 0 & -1 & 530 & 5 & 170 & 6 & 110.09 \\
\hline $\mathrm{T} 23$ & 0 & -1 & 1 & 0 & 530 & 5 & 190 & 8 & 104.42 \\
\hline $\mathrm{T} 24$ & 0 & 0 & 0 & 0 & 530 & 7 & 170 & 8 & 130.56 \\
\hline $\mathrm{T} 25$ & 1 & 0 & 0 & -1 & 550 & 7 & 170 & 6 & 109.87 \\
\hline T26 & 0 & 1 & 1 & 0 & 530 & 9 & 190 & 8 & 114.14 \\
\hline $\mathrm{T} 27$ & 1 & -1 & 0 & 0 & 550 & 5 & 170 & 8 & 119.85 \\
\hline $\mathrm{T} 28$ & -1 & 0 & 0 & -1 & 510 & 7 & 170 & 6 & 109.64 \\
\hline T29 & -1 & 0 & 0 & 1 & 510 & 7 & 170 & 10 & 114.64 \\
\hline T30 & 1 & 1 & 0 & 0 & 550 & 9 & 170 & 8 & 124.16 \\
\hline
\end{tabular}

the model F-value is 22.69, which indicates the model is statistically significant. There is only $0.01 \%$ chance that the"Model F-Value" could occur due to noise. The "Lack of Fit F-value" of 2.74 implies the Lack of Fit is not significant relative to the pure error, which is desirable. The coefficient of variation is $2.44 \%$, which clearly indicates the deviations between predicted and experimental values are small. Moreover, the model shows a high degree of precision and has a high degree of reliability in conducted experiments. For a well fitted model, the coefficient of determination $\left(\mathrm{R}^{2}\right)$ should not less than $80 \%$. A larger value of $\mathrm{R}^{2}$ close to unity shows that the mathematical model is suitable for fitting the actual data. However, a higher value of $\mathrm{R}^{2}$ does not mean the regression model is good, as $\mathrm{R}^{2}$ increase when variables are added. $\mathrm{R}_{\text {adj }}{ }$ is often to be used in testing the fit of a regression model. The value of $\mathrm{R}^{2}=0.9549$ indicates that $95.49 \%$ of the total variations can be explained by the regression model. The value of the $\mathrm{R}^{2}{ }_{\text {Adj }}=0.9128$ shows that $91.28 \%$ of the total variations can be explained by the regression model when considering the significant factors, which indicated the prediction model had an adequate approximation to the actual values.

$H V$ is expressed as the nonlinear function of the input process parameters in coded form. The model based on BBD is represented in Eq. 8. The actual values of the response are compared with model predicted values (Figure 4). It 
Table 4. ANOVA test for prediction model

\begin{tabular}{|c|c|c|c|c|c|}
\hline Source & Sum of Squares & $\mathrm{df}$ & Mean Square & F Value & P-value \\
\hline Model & 2507.89 & 14 & 179.13 & 22.69 & $<0.0001$ \\
\hline$X_{1}$ & 170.63 & 1 & 170.63 & 21.61 & 0.0003 \\
\hline$X_{2}$ & 181.35 & 1 & 181.35 & 22.97 & 0.0002 \\
\hline$X_{3}$ & 165.17 & 1 & 165.17 & 20.92 & 0.0004 \\
\hline$X_{4}$ & 136.28 & 1 & 136.28 & 17.26 & 0.0008 \\
\hline$X_{1} X_{2}$ & 13.62 & 1 & 13.62 & 1.72 & 0.2089 \\
\hline$X_{1} X_{3}$ & 12.67 & 1 & 12.67 & 1.61 & 0.2245 \\
\hline$X_{1} X_{4}$ & 21.02 & 1 & 21.02 & 2.66 & 0.1236 \\
\hline$X_{2} X_{3}$ & 5.55 & 1 & 5.55 & 0.70 & 0.4151 \\
\hline$X_{2} X_{4}$ & 99.60 & 1 & 99.60 & 12.61 & 0.0029 \\
\hline$X_{3} X_{4}$ & 0.91 & 1 & 0.91 & 0.12 & 0.7387 \\
\hline$X_{1}^{2}$ & 122.84 & 1 & 122.84 & 15.56 & 0.0013 \\
\hline$X_{2}^{2}$ & 510.40 & 1 & 510.40 & 64.64 & $<0.0001$ \\
\hline$X_{3}^{2}$ & 990.93 & 1 & 990.93 & 125.50 & $<0.0001$ \\
\hline$X_{4}^{2}$ & 658.73 & 1 & 658.73 & 83.43 & $<0.0001$ \\
\hline Residual & 118.44 & 15 & 7.90 & & \\
\hline Lack of Fit & 100.15 & 10 & 10.02 & 2.74 & 0.1388 \\
\hline Pure Error & 18.29 & 5 & 3.66 & & \\
\hline Cor Total & 2626.33 & 29 & & & \\
\hline
\end{tabular}

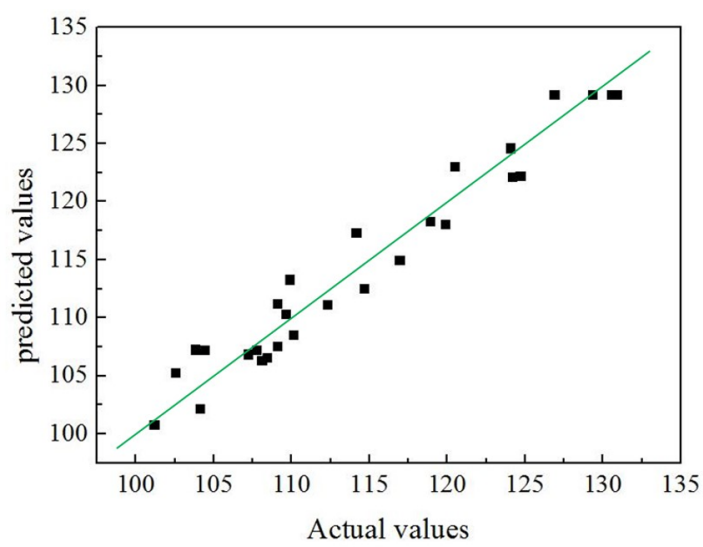

Figure 4. The comparison between predicted and actual value for Vickers hardness

has been found that the predicted values obtained for the model have a slight deviation from the ideal line, $\mathrm{y}=\mathrm{x}$ line. However, the majority of the data points are observed to lie close to the ideal line.

$$
\begin{gathered}
H V=129.23+3.77 X_{1}+3.89 X_{2}+3.71 X_{3}+ \\
\text { 3.37 } X_{4}-1.84 X_{1} X_{2}+1.78 X_{1} X_{3}+2.29 X_{1} X_{4}+1.18 X_{2} X_{3}+(8) \\
4.99 X_{2} X_{4}+0.48 X_{3} X_{4}-4.23 X_{1}^{2}-8.63 X_{2}^{2}-12.02 X_{3}^{2}-9.80 X_{4}^{2}
\end{gathered}
$$

The significance tests have been carried out for all terms of the fitted models. The terms, $X_{1}, X_{2}, X_{3}, X_{4}, X_{2} X_{4}, \mathrm{X}^{2}{ }_{1}, \mathrm{X}_{2}^{2}$, $\mathrm{X}_{3}^{2}, \mathrm{X}_{4}^{2}$, are significant terms as their $\mathrm{P}$-values are less than 0.05 , which makes a significant contribution to the response.
In the same way, the terms, $X_{1} X_{2}, X_{1} X_{3}, X_{1} X_{4}, X_{2} X_{3}, X_{3} X_{4}$, are insignificant terms. It is worth stressing that, the square terms of $\mathrm{X}_{1}{ }_{1}, \mathrm{X}_{2}{ }_{2}, \mathrm{X}_{3}{ }_{3}$ and $\mathrm{X}_{4}{ }_{4}$ are observed to have less than P-values of 0.05 , suggesting the relationship between $T_{\mathrm{s}}, t_{\mathrm{s}}$, $T_{\mathrm{a}}$ and $t_{\mathrm{a}}$ with the response $H V$ might be non-linear in nature.

\subsection{Effect of heat treatment process parameters on Vickers hardness}

The dimensional response surface and matching contour plots are drawn, establishing an evaluation of the interaction effects of process parameters. These plots represent the regression function of two process parameters, while the other variables are kept at the center levels. Response surface plot for the response Vickers hardness is presented in Figure 5. It is clear form the figure that solution treatment temperature $\left(T_{\mathrm{s}}\right)$, solution treatment time $\left(t_{\mathrm{s}}\right)$, ageing temperature $\left(T_{\mathrm{a}}\right)$ and ageing time $\left(t_{\mathrm{a}}\right)$ show significant contribution towards $H V$. The interactions between the variables, solution treatment temperature $\left(T_{\mathrm{s}}\right)$ and solution treatment time $\left(t_{\mathrm{s}}\right)$, solution treatment temperature $\left(T_{\mathrm{s}}\right)$ and ageing temperature $\left(T_{\mathrm{a}}\right)$, solution treatment temperature $\left(T_{\mathrm{s}}\right)$ and ageing time $\left(t_{\mathrm{a}}\right)$, are significant.

Referring to Figure 5(a), when the ageing temperature $\left(T_{\mathrm{a}}\right)$ and time $\left(t_{\mathrm{a}}\right)$ are kept at their center levels, the $H V$ is drastically increased with increasing both solution treatment temperature $\left(T_{\mathrm{s}}\right)$ and time $\left(T_{\mathrm{s}}\right)$. However, the further increase in solution treatment temperature $\left(T_{\mathrm{s}}\right)$ and time $\left(T_{\mathrm{s}}\right)$ will not give an increase of $H V$ and may even have the negative 

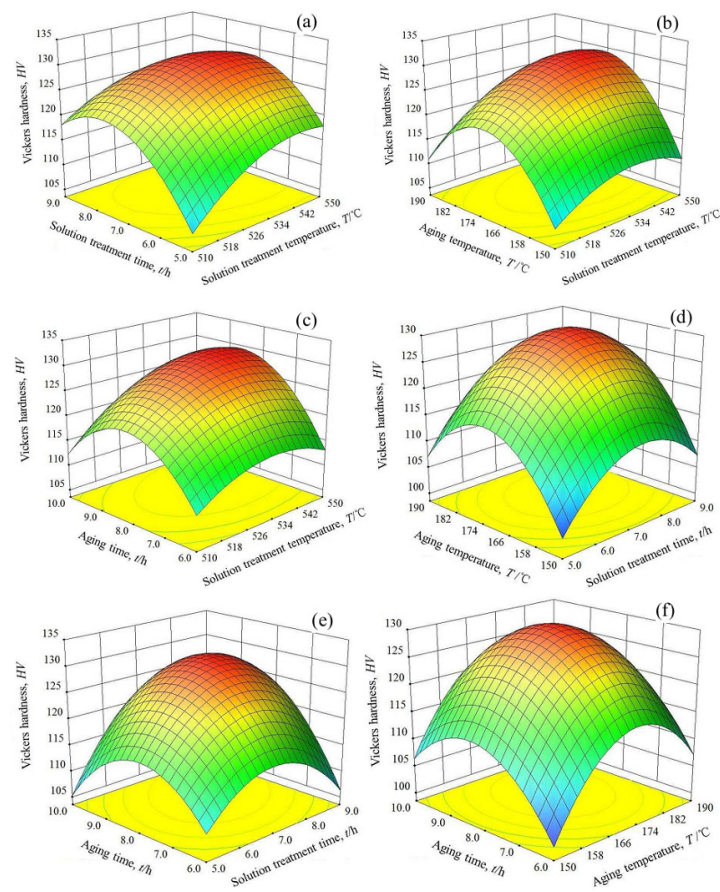

Figure 5. Response surface plot

effect on it. This is because the increase of solution treatment temperature $\left(T_{\mathrm{s}}\right)$ and time $\left(T_{\mathrm{s}}\right)$ leads to the incipient melting of phases and coarsening of eutectic silicon particles.

Regarding Figure 5(b), if the time of solution treatment $\left(t_{\mathrm{s}}\right)$ and ageing $\left(t_{\mathrm{a}}\right)$ are kept at their center levels, the $H V$ increases with increasing both temperature of solution treatment $\left(T_{\mathrm{s}}\right)$ and ageing $\left(T_{\mathrm{a}}\right)$ in the beginning. However, further increase in ageing temperature $\left(T_{\mathrm{s}}\right)$ leads to a significant decrease in $H V$. This means that increasing the ageing temperature $(T)$ above about $175^{\circ} \mathrm{C}$ is detrimental, which may result in overageing and coarsening of precipitates.

In Figure 5(c), for the constant values of solution treatment time $\left(t_{\mathrm{s}}\right)$ and ageing temperature $\left(T_{\mathrm{a}}\right)$, the $H V$ is increased with increasing ageing time $\left(t_{\mathrm{a}}\right)$ when the time is less than about 8 hours. But over time, the $H V$ decreases with increasing ageing time $\left(t_{\mathrm{a}}\right)$. This can be attributed to either the coarsening of $\beta^{\prime \prime}$ phase or the substitute of $\beta^{\prime \prime}$ phase to $\beta^{\prime}$ phase when the ageing time exceeds 8 hours.

In Figure 5(d), with the increase in both solution treatment time $\left(t_{\mathrm{s}}\right)$ and ageing temperature $\left(T_{\mathrm{a}}\right)$, the $H V$ significantly increases initially and later decreases with further increasing solution treatment time $\left(t_{\mathrm{s}}\right)$ and ageing temperature $\left(T_{\mathrm{a}}\right)$. The best $H V$ is achieved approximately at the middle of the parameter values.

Figure 5 (e) and Figure 5 (f) show the same trend with the above analysis.

\subsection{Optimization of heat treatment process}

Through above analysis, the response value for $H V$ has an optimal solution. The optimization problem of RSM can be solved by techniques of sequential approximation optimization (SAO) method. The optimization results of heat treatment process, $131.64 \mathrm{HV}$, are shown in Figure 6. The optimum process parameters are found to be solution treatment temperature of $540.28^{\circ} \mathrm{C}$, solution treatment time of $7.55 \mathrm{~h}$, ageing temperature of $174.23^{\circ} \mathrm{C}$, ageing time of $8.61 \mathrm{~h}$.

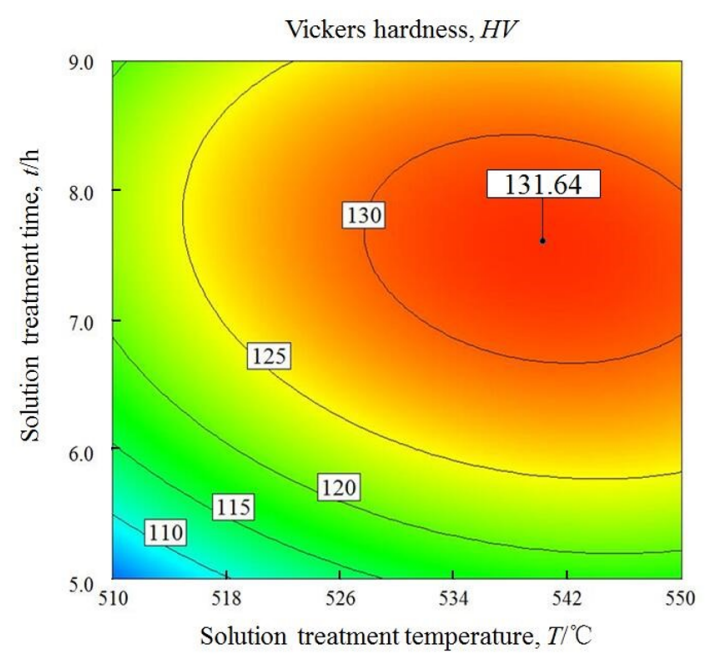

Figure 6. The optimization results of heat treatment process

\subsection{Further experiments}

The optimized heat treatment process was taken on the sprue of ring parts casting. The sprue with a diameter of $80 \mathrm{~mm}$ was sectioned along the radial direction (as shown in Figure 7). The microstructures of the sprue before and after heat treatment with different distance from the center are shown in Figure 8. The $H V$ of sprue and the secondary dendrite arm space (SDAS) were measured along the radius. The results are shown in Figure 9.

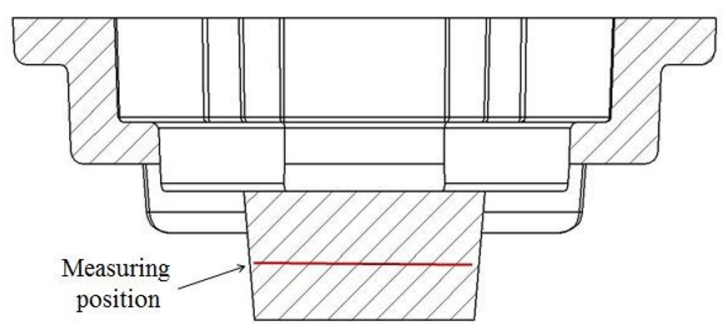

Figure 7. Sectional view and measuring position

During solution treatment, atoms diffuse through the matrix to reduce the concentration gradient, forming a homogenous solid solution. The time needed for homogenization is affected by the diffusing space influenced by the quality of the microstructure measured by $\mathrm{SDAS}^{3}$. The microstructure of samples shows a different SDAS distribution, as shown in Figure 8. SDAS decreases with the increasing distance from 

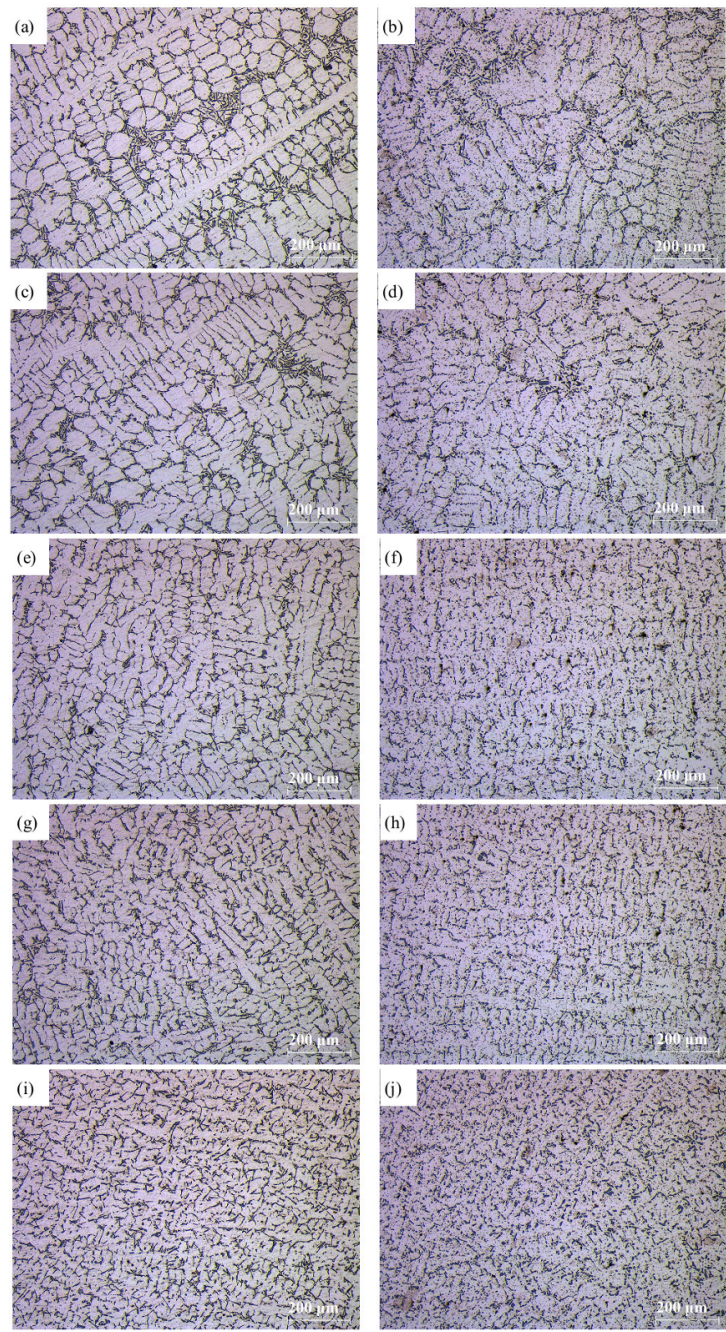

Figure 8. Microstructures of the sprue before ((a), (c), (e), (g), (i)) and after ((b), (d), (f), (h), (j)) heat treatment with different distance from the center (a) and (b) $3 \mathrm{~mm}$; (c) and (d) $11 \mathrm{~mm}$; (e) and (f) $19 \mathrm{~mm}$; (g) and (h) $27 \mathrm{~mm}$; (i) and (j) $35 \mathrm{~mm}$

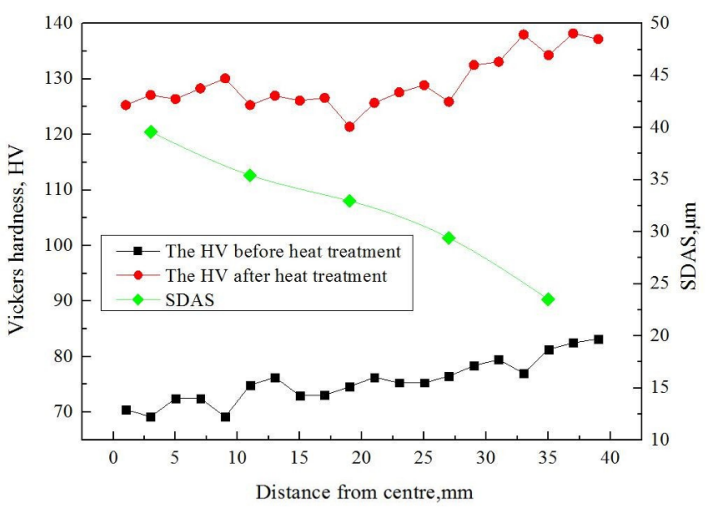

Figure 9. The $H V$ and SDAS alone the sprue radius the center due to different cooling rate from surface to center when the casting solidifies. The mechanical properties are correlated to the average grain size, which is learned from Hall-Petch equation. The $H V$, which is directly correlated to the microstructure, shows the increasing trend with increasing distance from center both before and after heat treatment.

The average $H V$ before heat treatment is $75.6 \mathrm{HV}$. After the heat treatment, average $H V$ reaching 129.3 increases more than $71 \%$. The percentage error between the predicted and the experimental value of $H V$ is $-1.78 \%$. It demonstrates the developed prediction model is adequate accurate mathematical models.

\section{Conclusions}

1) The non-linear mathematical model based on BBD has been developed for the response surface Vickers hardness. The results of significance and ANOVA tests have proved the prediction model have an adequate approximation to the actual values. The significance test shows the relationship between solution treatment temperature $\left(T_{\mathrm{s}}\right)$, solution treatment time $\left(t_{\mathrm{s}}\right)$, ageing temperature $\left(T_{\mathrm{a}}\right)$ and ageing time $\left(t_{\mathrm{a}}\right)$ with the response Vickers hardness $(H V)$ might be non-linear in nature.

2) The dimensional response surface and matching contour plots were drawn, establishing an evaluation of the interaction effects of process parameters. The interactions between the variables, solution treatment temperature $\left(T_{\mathrm{s}}\right)$ and solution treatment time $\left(t_{\mathrm{s}}\right)$, solution treatment temperature $\left(T_{\mathrm{s}}\right)$ and ageing temperature $\left(T_{\mathrm{a}}\right)$, solution treatment temperature $\left(T_{\mathrm{s}}\right)$ and ageing time $\left(t_{\mathrm{a}}\right)$, are significant. When two process parameters are kept at their center levels, the $H V$ is increased with increasing the other variables in the beginning. However, the further increase in process parameters leads to a significant decrease in $H V$.

3) The optimum heat treatment process parameters are found to be solution treatment temperature of $540.28^{\circ} \mathrm{C}$, solution treatment time of $7.55 \mathrm{~h}$, ageing temperature of $174.23^{\circ} \mathrm{C}$, ageing time of $8.61 \mathrm{~h}$. Further experiments found the $H V$ shows the increasing trend with increasing distance from the center of the cylindrical sprue both before and after heat treatment. After the heat treatment, average $H V$ reaching $129.3 \mathrm{HV}$ increases more than $71 \%$.

\section{Acknowledgments}

This work is supported by the National Natural Science Foundation of China (Nos.U1610123, 51674226, 51574207, 
51574206, 51274175), International Cooperation project of the Ministry of Science and Technology of China (No.2014DFA50320), The Science and Technology Major Project of Shanxi Province(No.MC2016-06), International Science and technology cooperation project of Shanxi Province(No.2015081041), Research Project Supported by Shanxi Scholarship Council of China, No.2016Key 2).Transformation of Scientific and Technological Achievements Special Guide Project of Shanxi Province (No.201604D131029).

\section{References}

1. Zhang M, Zhang WW, Zhao HD, Zhang DT, Li YY. Effect of pressure on microstructures and mechanical properties of Al$\mathrm{Cu}$-based alloy prepared by squeeze casting. Transactions of Nonferrous Metals Society of China. 2007;17(3):496-501. DOI: 10.1016/S1003-6326(07)60122-8

2. Dong PY, Zhao HD, Chen FF, Li JW. Microstructures and properties of $\mathrm{A} 356-10 \% \mathrm{SiC}$ particle composite castings at different solidification pressures. Transactions of Nonferrous Metals Society of China. 2013;23(8):2222-2228. DOI: 10.1016/ S1003-6326(13)62721-1

3. Sjölander E, Seifeddine S. The heat treatment of Al-Si-Cu-Mg casting alloys. Journal of Materials Processing Technology. 2010;210(10):1249-1259. DOI: 10.1016/j.jmatprotec. 2010.03.020

4. Rometsch PA, Arnberg L, Zhang DL. Modelling dissolution of $\mathrm{Mg}_{2} \mathrm{Si}$ and homogenisation in Al-Si-Mg casting alloys. International Journal of Cast Metals Research. 1999;12(1):1-8.

5. Rometsch PA, Schaffer GB, Taylor JA. Mass balance characterisation of Al-7Si-Mg alloy microstructures as a function of solution treatment time. International Journal of Cast Metals Research. 2001;14(1):59-69.

6. Alhawari KS, Omar MZ, Ghazali MJ, Salleh MS, Mohammed MN. Dry sliding wear behaviour of thixoformed hypoeutectic Al-Si-Cu alloy with different amounts of magnesium. Composite Interfaces. 2016;23(6):519-531. DOI: 10.1080/09276440.2016.1164496

7. Li DF, Cui CX, Wang X, Wang QZ, Chen C, Liu SQ. Microstructure evolution and enhanced mechanical properties of eutectic Al-Si die cast alloy by combined alloying $\mathrm{Mg}$ and La. Materials \& Design. 2016;90:820-828. DOI: 10.1016/j.matdes.2015.10.078

8. Shivkumar S, Ricci S, Keller C, Apelian D. Effect of solution treatment parameters on tensile properties of cast aluminum alloys. Journal of Heat Treating. 1990;8(1):63-70.
9. Yang CL, Li YB, Dang B, Lü HB, Liu F. Effects of cooling rate on solution heat treatment of as-cast A356 alloy. Transactions of Nonferrous Metals Society of China. 2015;25(10):3189-3196. DOI: 10.1016/S1003-6326(15)63952-8

10. Chaudhury SK, Apelian D. Effects of $\mathrm{Mg}$ and $\mathrm{Cu}$ content on quench sensitivity of $\mathrm{Al}-\mathrm{Si}-\mathrm{Mg}$ alloy. International Journal of Metalcasting. 2016;10(2):138-146. DOI: 10.1007/s40962016-0020-z

11. Dang B, Liu CC, Liu F, Liu YZ, Li YB. Effect of as-solidified microstructure on subsequent solution-treatment process for A356 $\mathrm{Al}$ alloy. Transactions of Nonferrous Metals Society of China. 2016;26(3):634-642. DOI: 10.1016/S1003-6326(16)64152-3

12. Colley LJ, Wells MA, Poole WJ. Microstructure-strength models for heat treatment of Al-Si-Mg casting alloys I: microstructure evolution and precipitation kinetics. Canadian Metallurgical Quarterly. 2014;53(2):125-137. DOI: 10.1179/1879139513Y.0000000112

13. Alfonso I, González G, Lara G, Rodríguez M, Domínguez M, Tellez MG, et al. Fractal analysis of the heat treatment response for multiphase Al alloys. Materials Research. 2016;19(3):628639. DOI: 10.1590/ 1980-5373-MR-2015-0755

14. Alexopoulos ND, Pantelakis SG. Quality evaluation of A357 cast aluminum alloy specimens subjected to different artificial ageing treatment. Materials \& Design. 2004;25(5):419-430.

15. Suarez MA, Figueroa I, Cruz A, Hernandez A, Chavez JF. Study of the Al-Si-X system by different cooling rates and heat treatment. Materials Research. 2012;15(5):763-769. DOI: 10.1590/S1516-14392012005000103

16. Mukherjee I, Ray PK. A review of optimization techniques in metal cutting processes. Computers \& Industrial Engineering. 2006; 50(1-2):15-34. DOI: 10.1016/j.cie.2005.10.001

17. Patel MGC, Krishna P, Parappagoudar MB. Modelling of squeeze casting process using design of experiments and response surface methodology. International Journal of Cast Metals Research. 2015;28(3):167-180. DOI: 10.1179/1743133614Y.0000000144

18. Wang H, Li EY, Li GY. Optimization of drawbead design in sheet metal forming based on intelligent sampling by using response surface methodology. Journal of Materials Processing Technology. 2008;206(1-3):45-55. DOI: 10.1016/j.jmatprotec.2007.12.002

19. Horng JT, Liu NM, Chiang KT. Investigating the machinability evaluation of Hadfield steel in the hard turning with $\mathrm{Al}_{2} \mathrm{O}_{3} / \mathrm{TiC}$ mixed ceramic tool based on the response surface methodology. Journal of Materials Processing Technology. 2008;208(1-3):532541. DOI: $10.1016 /$ j.jmatprotec.2008.01.018 